\title{
Impact of climate change on agriculture production and its sustainable solutions
}

\author{
Naveen Kumar Arora ${ }^{1}$ \\ Published online: 27 June 2019 \\ (c) Society for Environmental Sustainability 2019
}

Climate change is one of the most defining concerns of today's world and has greatly reshaped or in process of altering earth's ecosystems. Although climate change has been a constant process on earth, but in recent times, approximately last 100 years or so, the pace of this variation has increased manifolds. Due to the anthropogenic activities the average temperature has risen by $0.9{ }^{\circ} \mathrm{C}$ since nineteenth century, mainly due to greenhouse gas (GHG) emissions in the atmosphere. As per estimates this rise is expected to be $1.5^{\circ} \mathrm{C}$ by 2050 or may be even more, the way deforestation is occurring, GHG emission is increasing and soil, water bodies and air are being polluted. The unprecedented hike in temperature has resulted in increased events of droughts, floods, irregular patterns of precipitation, heat waves and other extreme happenings throughout the globe. As per the annual report of Weather, Climate and Catastrophe Insight, natural disasters alone have caused economic loses in tune of USD 225 billion across the world in 2018 and since 2016 the losses due to natural calamities have crossed USD 200 billion per year. About $95 \%$ of these losses are attributed to weather related incidences, of which cyclones, floods and droughts are the key players and are directly related to climate change. Altogether, the impact of climate change is very comprehensive but its far reaching effects are now clearly visible on agricultural sector, on which relies the food production and economy of the world. It is also worth noting that world population is expected to reach 9.7 billion by 2050 which would magnify the pressure on agricultural lands to meet the growing food demands already affected by the impact of climate change. As climate change and agriculture have inextricable links, abrupt changes in climatic conditions at such a rapid pace has threatened the food security at global scale. World Food Programme (WFP) report

Naveen Kumar Arora

nkarora.bbau@gmail.com

1 Department of Environmental Science, Babasaheb Bhimrao Ambedkar University, Lucknow, UP, India of 2018 revealed that increase in crop yield per hectare is significantly slower as compared to rates of rising population. As per Food and Agriculture Organization (FAO) data published in 2016, if the current situation of GHG emissions and climate change continue then by the year 2100 there will be decline in the production of major cereal crops (20-45\% in maize yields, $5-50 \%$ in wheat and $20-30 \%$ in rice). Hence if the trends continue, in very near future crop losses may increase at an unprecedented rate which will substantially contribute to reduced production, spiked food prices, and it will become difficult to cope up with rising needs of growing population.

The increasing demand of food due to ever growing population have resulted in intensive agricultural practices including unprecedented use of agro-chemicals, livestock generation (for meat and other source of income), exploitation of water resources etc. This has further aggravated the situation by release of GHG (due to agricultural activities) and resulting in pollution of natural resources. Forests act as a sink to the increasing amount of $\mathrm{CO}_{2}$ but unchecked rate of deforestation (mainly for development and agriculture) have imbalanced the natural process of carbon cycle. This has increased the amount of carbon footprint and induced uneven pattern of climate resulting in a variety of adverse effects which have major impact on agricultural production.

Climate change is resulting into a very high rate of land degradation causing enhanced desertification and nutrient deficient soils. The menace of land degradation is increasing by the day and has been characterized as a major global threat. According to Global Assessment of Land Degradation and Improvement (GLADA) a quarter of land area around the globe can now be marked as degraded. Land degradation is supposed to influence lives of 1.5 billion people and 15 billion tons of fertile soil is lost every year due to anthropogenic activities and climate change. Land degradation is resulting in mass migrations and as per a report published by United Nations Environment Programme in 2017, 500 million hectares of farmland has been abandoned 
due to drought and dissertification resulting in major social and environmental constraints. Extreme drought conditions, frequently occurring due to climate change, exacerbate the productivity of crops by causing nutrient immobilization and salt accumulation in soils making them dry, unhealthy, saline and finally infertile. Such barren lands become non-arable with course of time and are eventually abandoned by farmers leading to economic losses and social issues. Projected climate variations are not limited to only increase in drought conditions. Climate change has also resulted in increased and sporadic incidences of floods in last few years. Report by European Academies' Science Advisory Council (EASAC) suggests that extreme events including floods have increased by $50 \%$ in last 10 years and are now occurring at rate of four times higher than in comparison to 20 years back. Heavy floods in Kerala, India, in 2018 are a glaring example to showcase this. These floods have resulted in washout of top soil and nutrients from the soil, resulting in low productivity for several years to come, unless and until corrective and pro-active remediation strategies are not worked upon. Rise in sea levels or prevalence of heavy rainfall could result in decline of agricultural lands in coastal regions. This has also resulted in salinity of soils in coastal regions leading to stresses in crops such as decreased respiration, photosynthesis and transpiration, ultimately jeopardizing food availability and security in such regions.

All these climate related disturbances would not only have drastic impacts on food distribution patterns but also on its quality and access. Not only this, it will also raise humanitarian concerns as food security is deeply entwined with public health and will create a vicious cycle of hunger, diseases and crime. FAO reports that rise in world hunger level is constantly increasing since 2014 and an increment in number of undernourished people have been observed from 804 million in 2016 to 824 million in 2017. These reports established the fact that achieving the target of sustainable development goals (SDG) by 2030, to eradicate hunger is still difficult to achieve. Therefore, implementing and adapting to actions/policies to mitigate the effects caused by climate variability are urgently required. This can be achieved by adopting climate smart agriculture system which is in line with FAO's vision of Sustainable Food and Agriculture goals. This includes developing resilient varieties of crops which can withstand abrupt stresses of temperature and precipitation, implementing biotic and sustainable agricultural methods, for example, application of bioinoculants/biofertilizers using tolerant plant growth promoting rhizobacteria (PGPR) and their metabolites and other methods of organic farming in order to promote yield of crops in extreme environments in a holistic and a sustainable way. Use of biofertilizers and biopesticides will result in decreased reliance on chemical fertilizers and pesticides. This will result in reduced emission of GHG and decrease in levels of soil, water and air pollution. Also, change in crop cultivars, sowing time and cultivation techniques (such as mixed cropping systems) to provide greater durability to crops in extreme events should be taken into account. Reclamation of marginal and degraded lands using resilient crops, by afforestation or by the use of beneficial soil microbes will not only result in increased agriculture productivity but also help in combating climate change. The marginal or drought impacted lands are characterized with very low soil organic matter and soil microbial biomass. As per United Nations Convention to Combat Dissertification (UNCCD) "restoring the soils of degraded ecosystems has the potential to store up to 3 billion tonnes of carbon annually". Phyto or rhizoremediation of such soils increase the organic matter which results in enhanced $\mathrm{CO}_{2}$ fixation in the soil. Soil and oceans are the biggest sinks of $\mathrm{CO}_{2}$, thus by increasing the soil organic matter and subsequent enhancement in yield or planting of perennial crops or through planned agro-forestry can result in decreasing the levels of GHGs, helping in combating the climate change and simultaneously resulting in reclamation of marginal or degraded lands. Furthermore, extensive data collection and field trials to assess the impact of prevailing climatic conditions in different agro-ecological zones can help in designing future strategies through computational simulation. Remote sensing and satellite imaging can also help in future predictions for the vulnerable agro-ecosystems and suggesting for the corrective measures by involving multi-disciplinary approach. This can also help in working out responses, preparedness and planning of managing the agro-ecosystems for extreme events such as water scarcity, heat waves, floods and so on. Connecting and sensitizing farmers to sustainable technologies and activities is of utmost importance as they are the ones who can play a major role in implementation of the ecological goals. Execution of policies and frameworks at global, national and regional levels is of paramount importance. For this we have to act in unification rather than make policies at state or national levels. International policies on climate change and agriculture are need of the hour but implementation has to be done at the ground level. Climate smart agriculture is also an important requirement for enhancing the yields and quality of production. Climate change and agriculture are strongly co-related. It is clear that the fast pace of climate change will have far reaching impact on agro-ecosystems and their productivity. Hence it is high time that we prepare ourselves for the up-coming challenges so as to combat the impact of climate change and ensure food security not only for humans but other living beings as well. It is also the endeavor of the journal "Environmental Sustainability" to report the green strategies to combat climate change and enhance agri-production through sustainable methods.

Publisher's Note Springer Nature remains neutral with regard to jurisdictional claims in published maps and institutional affiliations. 